ORIGINAL PAPER

Eur. J. Histochem.

45: 131-140, 2001

(C) Luigi Ponzio e figlio - Editori in Pavia

\title{
Hyaluronate and CD44 expression patterns in the human placenta throughout pregnancy
}

\author{
D. Marzioni ${ }^{1}$, C. Crescimanno ${ }^{2}$, D. Zaccheo ${ }^{3}$, R. Coppari ${ }^{1}$, C. B. Underhill ${ }^{4}$, and M. Castellucci ${ }^{1}$
}

${ }^{1}$ Institute of Normal Human Morphology, University of Ancona, Ancona, Italy and ${ }^{2}$ Institute of Human Anatomy and Histology, University of Verona, Verona, Italy ${ }^{3}$ Institute of Anatomy, University of Genova, Genova, Italy ${ }^{4}$ Department of Anatomy and Cell Biology, Georgetown Medical Center, Washington, DC, USA

Accepted: 11/10/00

Key words: hyaluronan, CD44, human placenta, immunohistochemistry

\section{SUMMARY}

Hyaluronan (HA) and CD44 are involved in several processes such as cell migration and differentiation. In the present study, we examined the expression and distribution of both hyaluronan and its cell surface receptor (CD44) in the human placenta, which is a rapidly growing and differentiating organ that plays a fundamental role in fetal life. Hyaluronan was detected by a specific biotinylated binding probe, termed b-PG. In the first half of gestation, HA was strongly expressed in the stroma of the mesenchymal villi which have been previously identified as responsible for the growth and differentation of the villous trees. The other villous types showed an intense staining only in the fetal vessel walls and in the connective tissue closely underlying the trophoblastic cover. In addition, hyaluronan positive staining was also apparent in a restricted rim of villous stroma directly apposed to extravillous cytotrophoblastic cell islands and cell columns. In full term placentas, all villi expressed HA in their stromal tissue with a more homogenous staining than in the first half of gestation. In contrast to hyaluronan, in the first trimester CD44 was restricted to some of the Hof- bauer cells which may be able to internalize hyaluronan, thus playing a significant role in its removal in early pregnancy. CD44 was primarily expressed starting from the $16^{\text {th }}$ week of gestation. At the end of pregnancy it was expressed in the various villous types, especially in stem villi. Moreover, the plasma membrane of some extravillous cytotrophoblastic cells in the basal plate and the large majority of the decidual cells showed a positive immunostaining for this receptor. Taken together, these data suggest that HA is strongly involved in early villous morphogenesis, whereas CD44 seem to be play an important role in tissue remodelling later in gestation.

\section{INTRODUCTION}

Hyaluronate (or hyaluronan) (HA) is a high molecular-mass polysaccharide composed of repeated disaccharide units, widely considered to be an integral component of the extracellular matrix (Laurent and Fraser, 1992; Goodison et al., 1999). It has been shown to be involved in several biological processes such as cell-cell and cell-matrix adhesion as well as cell motility (Alho and Underhill, 1989; Toole, 1991;

Correspondence to: M. Castellucci

E-mail: m.castellucci@popcsi.unian.it 
Laurent and Fraser, 1992; Turley, 1992). These biological processes seem to be mediated through receptors for HA that are present on the cell surface (Green et al., 1988; Underhill, 1992). HA is the principal ligand of CD44. The latter has been identified as an integral membrane glycoprotein of about $85 \mathrm{kDa}$ (Underhill et al., 1985; Lacy and Underhill, 1987; Goodison et al., 1999). Aruffo et al. (1990) have shown that this HA receptor belongs to the glycoprotein family CD44 which represents a group of transmembrane proteins performing a variety of functions (Underhill, 1992). The multiple CD44 protein isoforms are encoded by a single gene by alternative splicing and are further modified by a range of post-translational modifications (Stamenkovic et al., 1991; Goodison et al., 1999). In addition to its ability to bind HA in order to mediate cell-cell and cell-matrix adhesions, CD44 is involved in the degradation of HA by receptor mediated internalization, and subsequently, by the action of acid hydrolases (Culty et al., 1992; Underhill, 1992; Goodison et al., 1999).

It has become evident that HA and CD44 are expressed during a number of physiological and pathological events such as embryonic development, tumor invasiveness and cell proliferation (Goodison et al., 1999; Johnson et al., 2000; Callagy et al., 2000). During embryonic development, HA and CD44 seem to play an important role in morphogenesis (Toole, 1991; Campbell et al., 1995). Strong expression of $\mathrm{HA}$ in the extracellular matrix of embryonic organs has been observed during early stages of development. At these stages, HA may be required as a medium through which mesenchymal cells and blood vessels migrate (Toole, 1991; Goshen et al., 1996). In later developmental stages, the intense expression is followed by a subsequent loss of HA which is considered to occur through CD44-mediated degradation. This is in accordance with the observation that the expression of CD44 is inversely correlated to the presence of HA in some developing organs, such as the developing lung (Underhill et al., 1993) and the embryonic hair follicle (Underhill, 1993). This reduction of HA in the extracellular matrix causes tissue condensation (Toole, 1991) and restriction of invading tissue components (Brown and Papaioannou, 1992).

Increased expression of HA and CD44 seem to be related to malignant lesions. Heider et al. (1993), for example, demonstrated an increased expression of CD44 in invasive colon carcinomas and carcinoma metastases in contrast to a relatively weak expression in the normal human colon. Because of this and other similar observations (Faassen et al., 1992; Koopman et al., 1993; Thomas et al., 1992 and 1993; De La Torre et al., 1993; Endo and Terada, 2000), CD44's interaction with extracellular HA is thought to play an important role in motility and invasion of tumor cells and thus in the metastatic behaviour of various malignancies.

Cell proliferation is an important feature of a number of biological events, such as embryonic development and the formation of malignant tumors. Indeed, there are indications that the interaction of HA and its receptor may be involved in the process of proliferation, because their expression is found to be closely associated with proliferating epithelial cells, as in the deeper layers of skin (Wang et al., 1992) and other stratified squamous epithelia (Alho and Underhill, 1989). One possible explanation of this phenomenon is the presumption that proliferation could be controlled by the amount of CD44 expression on the cell surface, regulating CD44-HA mediated attachment of dividing cells to their extracellular substratum.

The various events considered above in which HA and CD44 play an important role are also events that occur during the development of the human placenta. The rapid growth of this organ is characterized by a high proliferation rate and by processes of differentiation and invasion (Benirschke and Kaufmann, 1995). Different types of villi develop in the human placenta. The so-called mesenchymal villi are continuously formed out of trophoblastic sprouts throughout pregnancy (Castellucci et al., 1990; Benirschke and Kaufmann, 1995). These villi are the forerunners of all other villous types and they are considered to be the basis for growth and differentiation of the villous trees (Castellucci et al., 1990; Benirschke and Kaufmann, 1995). For instance, in the first half of gestation, the mesenchymal villi are generally transformed into immature intermediate villi which, in turn, differentiate into stem villi. Two other structures responsible for placental growth are the cytotrophoblastic cell columns and cell islands (Benirschke and Kaufmann, 1995). They are mainly formed by extravillous cytotrophoblastic cells. Cell columns play a fundamental role in anchoring the chorionic villi to the basal plate and their trophoblastic cells invade the decidua. Since the pla- 
centa is a model of differentiative, invasive and proliferative processes, it was of interest to study this organ throughout pregnancy with regard to the expression patterns of $\mathrm{HA}$ and CD44.

\section{MATERIALS AND METHODS}

\section{Materials}

Twenty human placentas aged $6(n=3), 8(n=4)$, $10(\mathrm{n}=5), 12(\mathrm{n}=6), 15(\mathrm{n}=1)$ and $16(\mathrm{n}=1)$ weeks p.m. were obtained from clinically normal pregnancies interrupted by currettage for psycho-social or medical reasons, which were unlikely to affect placental structure and function. Ten full-term placentas were obtained from spontaneous deliveries after uncomplicated pregnancies.

\section{Tissue preparation}

Placental tissue was cut into small blocks. Some tissue blocks were snap-frozen in liquid nitrogen and stored at $-20^{\circ} \mathrm{C}$. Cryostat sections $(5 \mathrm{~m})$ were mounted on glass slides and were air dried at room temperature for a few minutes. The sections were fixed in $100 \%$ acetone at $4^{\circ} \mathrm{C}$ for $10 \mathrm{~min}$ and stored at $4^{\circ} \mathrm{C}$ until use (up to one night from sectioning). Other tissue blocks were fixed in $4 \%$ neutral buffered formalin at $4^{\circ} \mathrm{C}$ for up to $24 \mathrm{~h}$, dehydrated in a graded series of ethyl alcohol and embedded in paraffin at temperatures not exceeding $56^{\circ} \mathrm{C}$. Paraffin sections $(3-5 \mathrm{~m})$ were cut, stretched at $45^{\circ} \mathrm{C}$, allowed to dry and stored at $4^{\circ} \mathrm{C}$ until use.

\section{Binding probe and primary antibodies}

The binding probe for HA (b-PG) consisted of a biotinylated form of the hyaluronate-binding complex prepared from cartilage proteoglycan as previously described (Green et al., 1988). Previous studies have shown that the b-PG probe binds to HA with high affinity and specificity (Green et al., 1988; Alho and Underhill, 1989). For localization of the HA receptor, two different primary antibodies raised against CD44 were used:

- The monoclonal BU52-antibody (The Binding Site, Birmingham, U.K.), dilution 1:200 v/v;

- The monoclonal antibody NKI-P1 (kind gift of Dr. C. Figdor, Amsterdam, NL; Pals et al., 1989), directed against the standard form of CD44, dilution $1: 100 \mathrm{v} / \mathrm{v}$.

\section{b-PG histochemical staining and immunohisto-} chemistry

Histochemical and immunohistochemical reactions were performed using our own protocol (Aachen Kit; Frank et al., 1994) based on streptavidin-biotin-methodology. Frozen sections were processed without pre-treatment. Paraffin sections were deparaffinized using xylene and a graded series of ethanol and then preincubated with bromelin (Frank et al., 1994) or trypsin. For detection of CD44, no enzymatic preincubation was used. Frozen and paraffin sections were incubated with the b-PG probe or the primary antibodies (listed above) for $1 \mathrm{~h}$ at room temperature. Because the binding probe for HA is biotinylated, two steps of the Aachen Kit could be omitted (the incubation of tissues with non-immune serum and the incubation with the link antibody). For b-PG histochemical staining, and immunohistochemical detection of CD44, further steps were performed according to the method described by Frank et al. (1994). Most of the sections were counterstained with an alkaline toluidine blue-solution (frozen sections) or with hematoxylin (paraffin sections).

\section{Controls}

\section{Histochemical controls}

To exclude non-specific binding of $b-\mathrm{PG}$, the following controls were performed:

a) samples of the b-PG solution were preadsorbed with varying concentrations of HA (Sigma, St. Louis, MO, USA; the concentration range was $12-200 \mu \mathrm{g} / \mathrm{ml}$ );

b) the b-PG probe was applied to tissue sections previously incubated with varying concentrations of hyaluronidase (type V, Sigma H6254; the concentration range was $0.5-2 \mathrm{U} / \mathrm{ml}$ in $0.1 \mathrm{M}$ Tris$\mathrm{HCl}, \mathrm{pH} 7.4,37^{\circ} \mathrm{C}$ for $1 \mathrm{~h}$ ).

\section{Immunohistochemical controls}

The primary antibodies were replaced by $10 \%$ non-immune serum or PBS. Further controls were performed by omitting the secondary antibody. Human skin was used as positive control both for $\mathrm{HA}$ and CD44 detection in all the procedures described above. It showed the same staining patterns as previously described (Alho and Underhill, 1989; Wang et al., 1992). 


\section{RESULTS}

Preliminary studies revealed that the results were qualitatively identical using paraffin or frozen sections. We examined the ability of b-PG probe to bind to tissue hyaluronate under control conditions. Binding was attenuated or completely inhibited by the addition of relatively small amounts of hyaluronate. In a similar fashion, binding was also inhibited by the digestion with hyaluronidase. For the immunohistochemical localization of CD44, the monoclonal NKI-Pl generally gave a more intense immunoreaction product than the BU52antibody. However, because both antibodies showed an identical staining pattern, no separate description will be provided. Immunohistochemical controls were always negative.

\section{First half of pregnancy}

\section{Localization of HA}

One of the most striking results was the strong positive staining of the stroma of mesenchymal villi which are the newly sprouting villous outgrowths. Immature intermediate villi as well as stem villi showed only an intense staining pattern in the vessel wall (particularly in the media) as well as in the connective tissue underlying the trophoblastic cover. Capillaries of the paravascular network underneath the trophoblastic cover were also embedded in an HA-rich stroma (Fig. 1). The remaining villous stroma was weakly positive, with increased staining only where the mesenchymal villi were branching off from the parental immature intermediate ones. HA was also strongly expressed in a restricted rim of villous stroma directly apposed to extravillous cytotrophoblastic cell islands and cell columns. HA was not expressed between the epithelial cells of cell islands and cell columns (Fig. 2).
Although trophoblast usually showed no staining for HA, in a few villi the apical membrane of syncytiotrophoblast was weakly positive.

The chorionic plate was positive in the connective tissue surrounding the largest vessels. The basal plate was mostly negative. However, a few cells were partially surrounded by a spot-like reaction product.

\section{Localization of CD44}

In the first trimester of gestation, CD44 was detectable in some villi. Isolated macrophages in the villous stroma (Fig. 3) and some endothelial cells of small vessels showed immunoreactivity. Expression of CD44 was more readily detected from the 16th week of gestation. In these specimens, positive staining was observed in the stromal tissue of some larger villi (Fig. 4). The media of the fetal vessels was negative whereas the intima and the connective tissue surrounding the vessels showed a positive reaction product. The plasma membrane of a few extravillous cytotrophoblastic cells in the basal plate showed a rim of staining.

\section{Full-term placentas}

\section{Localization of HA}

Nearly all villi expressed HA in their stromal tissue with a more homogenous pattern than in the first half of gestation. The walls of villous arteries were positive for HA (Fig. 5). Positive staining for HA was also present in the stroma of the chorionic plate. Sometimes along the apical plasma membrane of the syncytiotrophoblast, regions of a thin reaction product were present, while the trophoblastic cytoplasm was negative. A strong immunostaining for HA was apparent in the stroma of chorionic villi that were partially embedded

Figs. 1/4 - (1)Staining pattern for HA in first trimester chorionic villi. The reaction product is strong in all the stroma of the mesenchymal villi (arrows) and in the media of the fetal vessels of the immature intermediate villus (IIV). In the latter HA is also present underneath the trophoblastic covering where capillaries of the paravascular network are present. Note the absence of staining in most of the stroma of the villous core of the immature intermediate villus. $10^{\text {th }}$ week of gestation. Paraffin section not

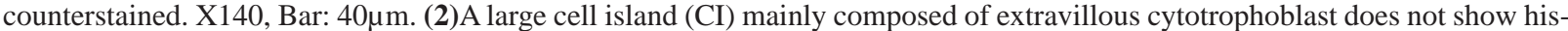
tochemical staining for HA. The latter is expressed in the core of the various types of chorionic villi with different staining pat-

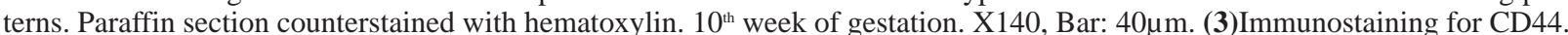
Note that very few stromal cells (arrowheads), mainly Hofbauer cells, are positive in the stroma of the placental villi. A maternal leukocyte (arrow) is also positive for CD44 in the intervillous space. $8^{\text {th }}$ week of gestation. Frozen section counterstained with

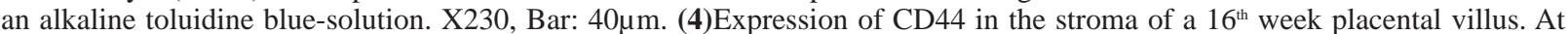
this stage of gestation CD44 becomes more prominently expressed. Paraffin section not counterstained. X140, Bar: 40 $\mu$ m. 


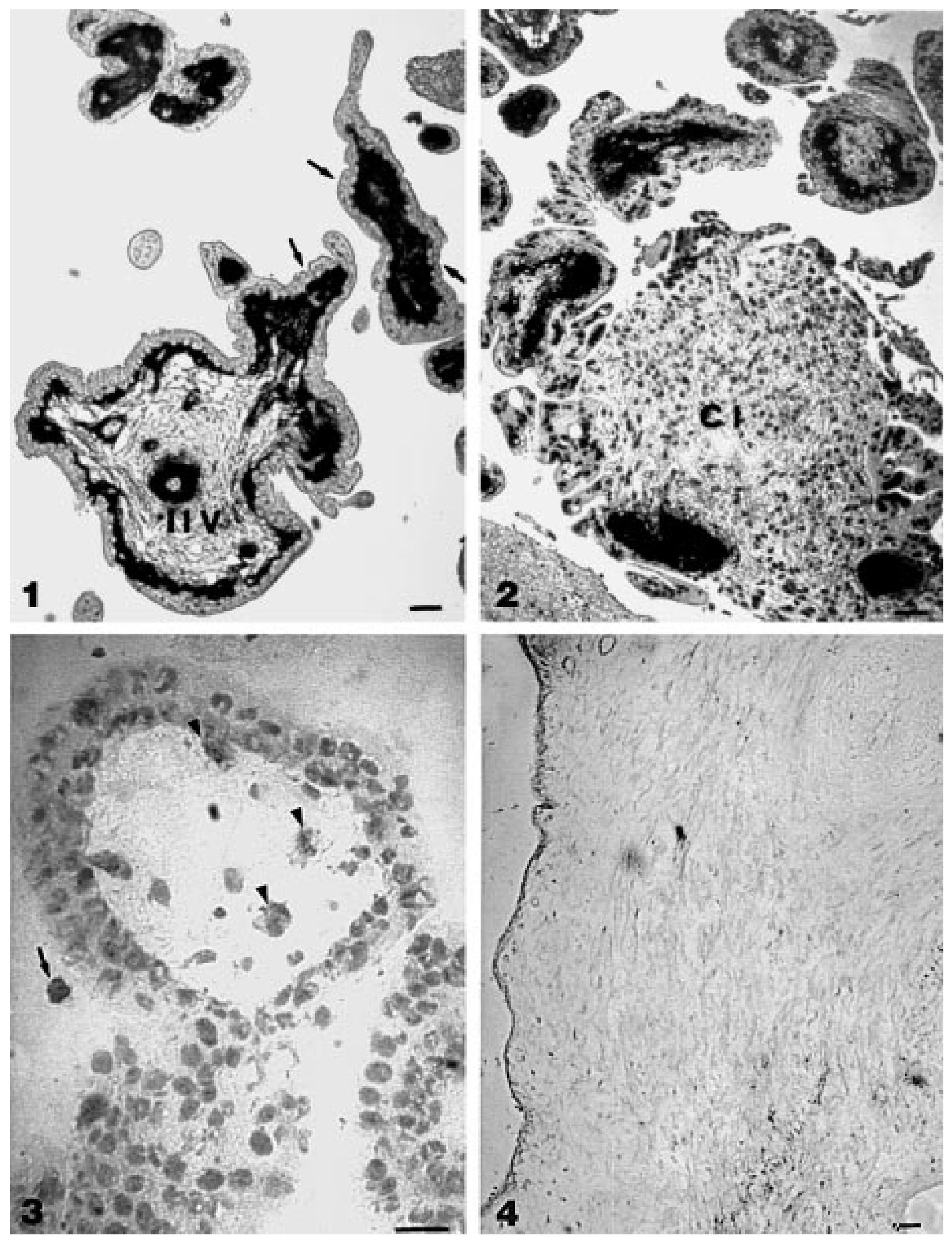



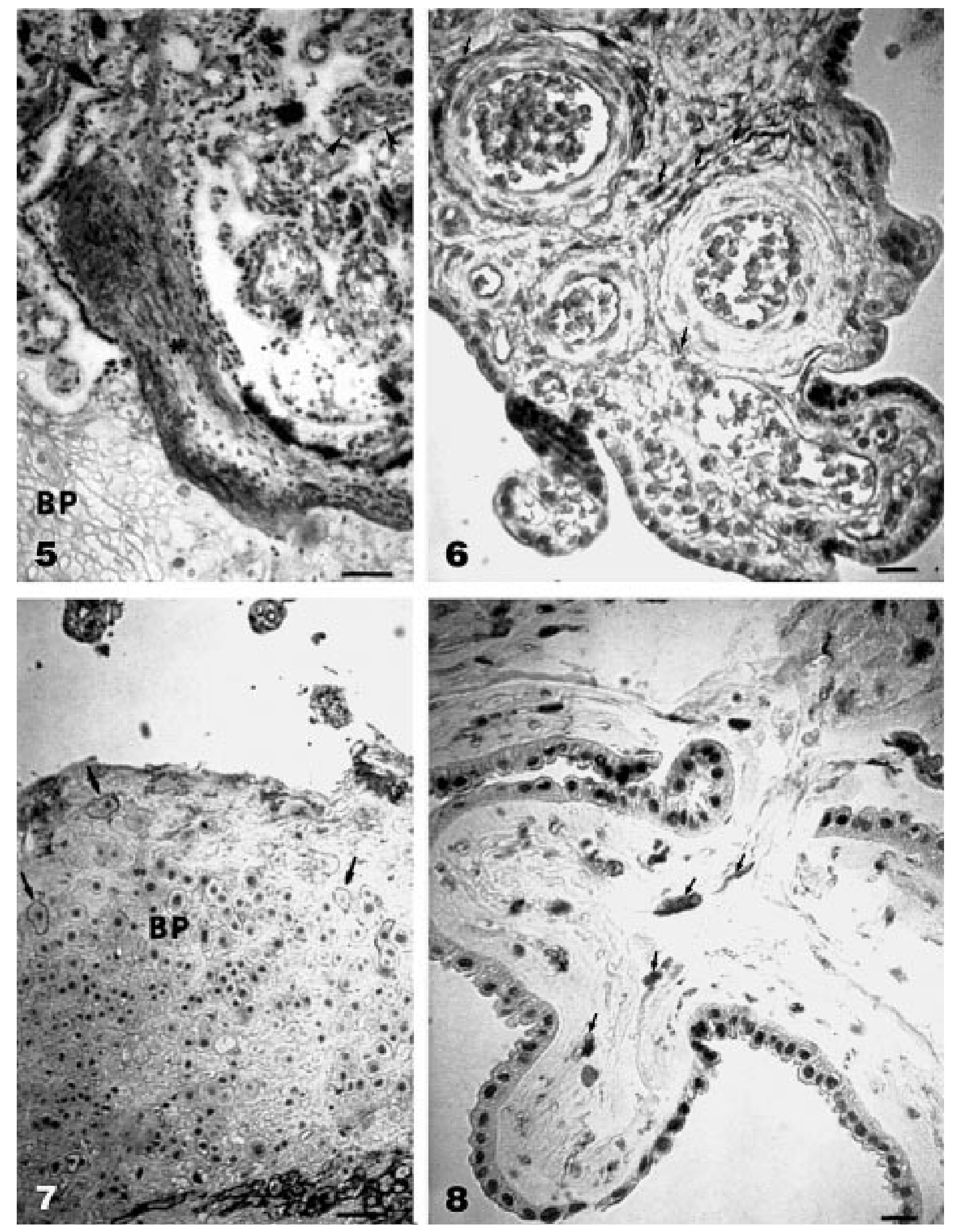
in the basal plate (Fig. 5). In addition, some cells in the basal plate were surrounded by a thin rim of positive staining for HA.

\section{Localization of CD44}

While the expression of CD44 was weak or absent in the villous stroma of specimens from the first trimester of gestation, evident immunoreactivity for CD44 was apparent at the end of gestation. Stem villi were clearly positive for CD44 (Fig. 6). However, in smaller villi the expression patterns of the receptor varied from a positive staining to a negative reaction product.

CD44 was clearly present in the intima of most of the large vessels, but absent from their media. Smaller vessels usually showed a positive staining in the intima, too (Fig. 6). Moreover, strong immunoreactivity was detectable along the plasma membrane of some extravillous cytotrophoblastic cells in the basal plate, whereas the large majority of the decidual cells showed positive immunostaining (Fig. 7).

The chorionic plate showed staining of numerous connective tissue cells and some extravillous trophoblastic cells. No reaction product was present in the amniotic epithelium (Fig. 8).

\section{DISCUSSION}

One of the most important findings of our study is the strong positive staining for HA in the mesenchymal villi, i.e. in those villi where the main angiogenic, proliferative and differentiative processes take place (Castellucci et al. 1990; Benirschke and Kaufmann, 1995). This suggests that HA plays a fundamental role in these processes. Indeed, HA may be required as a medium through which neovessel formation can take place, facilitating the migration and assembly of the different components of the vascu- lar wall (Underhill et al., 1993; Goshen et al., 1996). In addition, the presence of HA in the immature intermediate villi underlying the trophoblastic covering and surrounding the vessels of the paravascular capillary network underneath the trophoblastic cover, suggests that this molecule is readily available and produced as soon as new mesenchymal villi are formed from the immature intermediate ones (Castellucci et al., 1990). Sprouting of trophoblast and protrusion of mesenchyme with large amounts of HA into such trophoblastic sprouts can facilitate the formation of new mesenchymal villi. The abundance of HA in the mesenchymal villi is in contrast with the weak staining for this molecule in the core of the immature intermediate villi. Interestingly, the latter are gradually transformed into stem villi, which, on the other hand, show large amounts of $\mathrm{HA}$ in the second half of gestation (see also St. Jacques et al., 1993; Ponting and Kumar, 1995). These variations in the presence of HA could be related to modifications in the morphology of the villous stromal cells, which are responsible for the production of HA. It has been previously pointed out that these cells change their shape during differentiation of the villous tree; they are mostly small and roundish in the mesenchymal villi, elongated with large sail-like cytoplasmic processes in the immature intermediate villi and fibroblast-like in the stem villi (Castellucci and Kaufmann, 1982; Martinoli et al., 1984; Castellucci et al., 1990; Benirschke and Kaufmann, 1995). It is well established that alterations in the morphology of the connective tissue cells can influence various programs of gene expression including the production of various extracellular matrix molecules (Ben-Ze'ev, 1986; Werb et al., 1986). Thus, it could be that the trasformation of the roundish stromal cells of the mesenchymal villi into the large cells of the immature intermediate villi results in a strong decrease in the production of HA.

Figs. 5/8 - (5)Expression of HA in term placental chorionic villi. The staining pattern is particularly evident in the vessel walls (arrowheads). Note the strong reaction product in the stroma of a villus (*) in part embedded in the basal plate (BP). Frozen sec-

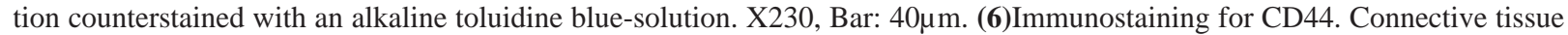
cells (arrows) of the villous stroma are positive, as are most of the intima cells. Note the absence of staining in the media of the

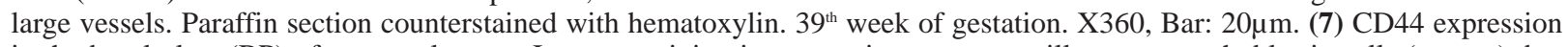
in the basal plate (BP) of a term placenta. Immunostaining is present in some extravillous cytotrophoblastic cells (arrows), but very strong labelling is observable in the decidual cells, located in the lower right-hand part of the figure. Frozen section counterstained with an alkaline toluidine blue-solution. X230, Bar: 40 $\mu \mathrm{m}$. (8)Immunostaining for CD44. Term placenta, amnion covering the chorionic plate. Numerous connective tissue cells (arrows) are positive. Paraffin section counterstained with hematoxylin. X 360, Bar: $20 \mu \mathrm{m}$. 
The presence of HA in the placental villi of the first and third trimester may have important implications concerning pressure variations in the intervillous space and in the chorionic villi. Pressure variations in the human placenta are, at least in part, related to the presence of contractile proteins in the stromal cells of the chorionic villi (Krantz and Parker, 1963; Wallenburg 1981; Castellucci and Kaufmann, 1982; Graf et al., 1992; Martinoli et al., 1994; Kohnen et al., 1995). Such pressure variations in the human placenta are necessary to facilitate a continuous renewal of the maternal blood layer in contact with the surface of the chorionic villi and the movement of fluids in the villous core (Castellucci and Kaufmann, 1982). HA, through its binding of large amounts of water forming hydrated gels even at low concentrations (Brown and Papaioannou, 1992), could play a role in modulating the intensity of the pressure and the movement of fluids in the chorionic villi.

It has been noted that during the development of hair follicles and lung, the expression of CD44 is inversely correlated to the presence of HA (Underhill, 1992; Underhill et al., 1993). The inverse relationship between HA and the expression of CD44 is also observable in the first trimester chorionic villi, where CD44 is only expressed by some Hofbauer cells. The fact that these macrophages bear the CD44 receptor at their surface could be related to the rapid morphogenic processes and tissue remodelling as well as the numerous different functions of this organ.

Both functionally and physically, the CD44 receptor can be divided into three major domains: the cytoplasmic domain, which mediates the interactions with the cytoskeleton; the middle domain, which is responsible for the lymphocyte homing; and the amino-terminal domain which binds to HA (Underhill,1992; Fujita et al., 1994). The observations that the cytoplasmic domain of CD44 colocalizes with cytoskeletal proteins has been related to its role in cell migration (Thomas et al., 1992; Laurent and Fraser, 1992; Handerson et al., 1994). Thus, the presence of CD44 on the surface of the Hofbauer cells might allow these cells to migrate, promoting a localized degradation of HA.

Brown and Papaioannou (1992) observed in the mouse endometrium that decidualization is accompanied by clearance of HA from the extracellular matrix and proposed that this phenomenon serves to restrict trophoblast invasion by the presentation of a non-permissive extracellular matrix substrate. It is possible that most of the decidual cells that are CD44-positive function to limit the trophoblastic invasion by reducing the hydration of the matrix and allowing enhanced adhesive interactions between adjacent decidual cells (Brown and Papaioannou, 1993).

\section{ACKNOWLEDGEMENTS}

The authors are indebted to Professor S. Cinti (Ancona, Italy) and to Professor P. Kaufmann (Aachen, Germany) for useful discussions. This investigation was supported by United States Health Services Grant HD26758 to Charles Underhill, the Italian Ministry of University (MURST) and the VIGONI programme to M. Castellucci. Miss M. Heinzelmann actively partecipated in the preparation of the first draft of the manuscript. We are grateful to Dr. P. Ferrara for technical assistance.

\section{REFERENCES}

Alho A.M., and Underhill C.B.: The hyaluronate receptor is preferentially expressed on proliferating epithelial cells. J. Cell Biol. 108, 1557-1565, 1989.

Aruffo A., Stamenkovic I., Melnick M., Underhill C.B., and Seed B.: CD44 is the principal cell surface receptor for hyaluronate. Cell 61, 1303-1313, 1990.

Ben-Ze'ev A.: The relationship between cytoplasmic organization, gene expression and morphogenesis. Trends Biochem. Sci. 11, 478-481, 1986.

Benirschke K., and Kaufmann P.: The patology of the human placenta, 3rd ed. Springer Verlag, New York, 1995

Brown J.J.G., and Papaioannou V.E.: Distribution of hyaluronan in the mouse endometrium during the periimplantation period of pregnancy. Differentiation 52, 61-68, 1992.

Callagy G., O’Grady A., Butler D., Leader M., and Kay E.: Expression of CD44 in uterine cervical squamous neoplasia: a predictor of microinvasion? Gynecol. Oncol. 76, 73-79, 2000.

Campbell S., Swann H.R., Aplin J.D., Seif M.W., Kimber S.J., and Elstein M.: CD44 is expressed throughout preimplantation human embryo development. Hum. Reprod. 10, 425-430, 1995.

Castellucci M., and Kaufmann P.: A three-dimensional study of the normal human placental villous core: II. Stromal architecture. Placenta 3, 269-286, 1982. 
Castellucci M., Scheper M., Scheffen I., Celona A., and Kaufmann P.: The development of the human placental villous tree. Anat. Embryol. 181, 117-128, 1990.

Culty M., Nguyen H.A., and Underhill C.B.: The hyaluronan receptor (CD44) participates in the uptake and degradation of hyaluronan. J. Cell Biol. 116, 1055-1062, 1992.

De la Torre, M., Well, A.F., Bergh, J., and Lindgren A.: Localization of hyaluronan in normal breast tissue, radial scar, and tubular breast carcinoma. Hum. Pathol. 24, 1294-1297, 1993.

Endo K., and Terada T.: Protein expression of CD44 (standard and variant isoforms) in hepatocellular carcinoma: relationships with tumor grade, clinicopathologic parameters, p53 expression, and patient survival. J. Hepatol. 32, 78-84, 2000.

Faassen, A.E., Schrager, J.A., Klein, D.J., Oegema, T.R., Couchman, J.R., and McCarthy J.B.: A cell surface chondroitin sulfate proteoglycan, immunologically related to CD44, is involved in type I collagen-mediated melanoma cell motility and invasion. J. Cell Biol. 116, 521-531, 1992.

Frank H.-G., Malekzadeh F., Kertschanska S., Crescimanno C., Castellucci M., Lang I., Desoye G., and Kaufmann, P.: Immunohistochemistry of two different types of placental fibrinoid. Acta Anat. 150, 55-68, 1994.

Fujita N., Yaegashi N., Ide Y., Sato S., Nakamura M., Ishiwata I., and Yajima A.: Expression of CD44 in normal human versus tumor endometrial tissues: possible implication of reduced expression of CD44 in lymph-vascular space involvement of cancer cells. Cancer Research. 54, 3922-3928, 1994.

Goodison S., Urquidi V., and Tarin D.: CD44 cell adhesion molecules. Mol. Pathol. 52, 189-196, 1999.

Goshen R., Ariel I., Shuster S., Hochberg A., Vlodavsky I., de Groot N., Ben-Rafael Z., and Stern R.: Hyaluronan, CD44 and its variant exons in human trophoblast invasion and placenta angiogenesis. Mol. Hum. Reprod. 2, 685-691, 1996.

Graf R., Frank H.G., and Öney T.: Risk assessment of prenatally-induced adverse health effects, Springer Verlag, Berlin, 1992.

Green S.J., Tarone G., and Underhill, C.B.: Distribution of hyaluronate receptors in the adult lung. J. Cell Sci. 89, 145156, 1988.

Handerson K.J., Edwards J.C.W., and Worrall J.G.: Expression of CD44 in normal and rheumatoid synovium and cultured synovial fibroblasts. Ann. Rheum. Dis. 53, 729-734, 1994.

Heider K.-H., Hofmann M., Hors E., van den Berg F., Ponta H., Herrlich P., and Pals S.T.: A human homologue of the rat metastasis-associated variant of CD44 is expressed in colorectal carcinomas and adenomatous polyps. J. Cell Biol. 120, 227-233, 1993.

Johnson P., Maiti A., Brown K.L., and Li R.: A role for the cell adhesion molecule CD44 and sulfation in leukocyte-endothelial cell adhesion during an inflammatory response? Biochem. Pharmacol. 59, 455-465, 2000.
Koopman G., Heider K.-H., Horst E., Adolf G.R., van den Berg F., Ponta H., Herrlich P., and Pals S.T.: Activated human lymphocytes and aggressive non-Hodgkin's lymphomas express a homologue of the rat metastasis-associated variant of CD44. J. Exp. Med. 177, 897-904, 1993.

Krantz K.E., and Parker J.C.: Contractile properties of the smooth muscle in the human placenta. Clin. Obstet. Gynecol. 6, 26-38, 1963

Kohnen G., Castellucci M., Hsi B.-L., Yeh C.-J. G., and Kaufmann P.: The monoclonal antibody GB42-a useful marker for the differentiation of myoblasts. Cell Tissue Res. 281, 231-242, 1995 .

Lacy B.E., and Underhill C.B.: The hyaluronate receptor is associated with actin filaments. J. Cell Biol. 105, 1395-1404, 1987.

Laurent T.C., and Fraser J.R.E.: Hyaluronan. FASEB J. 6, 2397-2404, 1992.

Martinoli C., Castellucci M., Zaccheo D., and Kaufmann P.: Scanning electron microscopy of stromal cells of human placental villi throughout pregnancy. Cell Tissue Res. 234, 647655,1984

Pals S.T., Horst E., Ossekoppele G.J., Figdor C.C., Scheper R.J., and Meyer C.J.L.M.: Expression of lymphocyte homing receptor (CD44) as a mechanism of dissemination in nonHodgkin's lymphomas. Blood 73, 995-998, 1989.

Ponting J.M., and Kumar S.: Isolation and characterisation of a hyaluronan binding protein, hyaluronectin, from human placenta and its colocalisation with hyaluronan. J. Anat. 186, $131-142,1995$.

St Jacques S., Dadi H.K., and Letarte M.: CD44 in human placenta: localization and binding to hyaluronic acid. Placenta $14,25-39,1993$.

Stamenkovic I., Aruffo A., Amist M., and Seed B.: The hematopoietic and epithelial forms of CD44 are distinct polypeptides with different adhesion potentials for hyaluronan-bearing cells. EMBO J. 10, 343-347, 1991

Thomas L., Byers H.R., Vink J., and Stamenkovic I.: CD44H regulates tumor cell migration on hyaluronate-coated substrate. J. Cell Biol. 118, 971-977, 1992.

Thomas L., Etoh T., Stamenkovic I., Mihm Jr. M.C., and Byers H.R.: Migration of human melanoma cells on hyaluronate is related to CD44 expression. J. Invest. Dermatol. $100,115-120,1993$.

Toole B.P.: Proteoglycans and hyaluronan in morphogenesis and differentiation. In E.D. Hay Ed., "Cell biology of extracellular matrix”. Plenum, New York, pp. 305-341, 1991

Turley E.A.: Hyaluronan and cell locomotion. Cancer. Met. Rev. 11, 21-30, 1992

Underhill C.B., Thurn A.L., and Lacy B.E.: Characterization and identification of the hyaluronate-binding site from membranes of SV-3T3 cells. J. Biol. Chem. 260, 8128-8133, 1985. 
Underhill C.: CD44: The hyaluronan receptor. J. Cell Sci. 103, 293-298, 1992.

Underhill C.B., Nguyen H.A., Shizari M., and Culty M. CD44 positive macrophages take up hyaluronan during lung development. Dev. Biol. 155, 324-336, 1993.

Wallenburg H.C.S.: Modulation and regulation of uteroplacental blood flow. Placenta (Suppl 1), 45-64, 1981.
Wang C., Tammi M., and Tammi R.: Distribution of hyaluronan and its CD44 receptor in the epithelia of human skin appendages. Histochemistry 98, 105-112, 1992.

Werb Z., Hembry R.M., Murphy G., and Aggeler J.: Commitment to expression of the metalloendopeptidases, collagenase and stromelysin: relationship of inducing events to changes in cytoskeletal architecture. J. Cell Biol. 102, 697-702, 1986. 